\title{
Spectacle Coverage and Spectacles Use among Elderly Population in Residential Care in the South Indian State of Andhra Pradesh
}

\author{
Srinivas Marmamula, ${ }^{1,2,3,4}$ L. V. Chandra Sekhar Ravuri, ${ }^{1,5}$ \\ Mei Ying Boon, ${ }^{4}$ and Rohit C. Khanna ${ }^{1}$ \\ ${ }^{1}$ Allen Foster Community Eye Health Research Centre, International Centre for Advancement of Rural Eye care, \\ L V Prasad Eye Institute, L V Prasad Marg, Banjara Hills, Hyderabad 500 034, India \\ ${ }^{2}$ Bausch \& Lomb School of Optometry, L V Prasad Eye Institute, Hyderabad 500 034, India \\ ${ }^{3}$ Dana Center for Preventive Ophthalmology, Wilmer Eye Institute at Johns Hopkins University, Baltimore, MD 21287, USA \\ ${ }^{4}$ School of Optometry \& Vision Science, University of New South Wales, Sydney 2033, Australia \\ ${ }^{5}$ Community Health \& Nutrition Office, Area Hospital, Kandukur, Prakasam District, Andhra Pradesh 523105, India
}

Correspondence should be addressed to Srinivas Marmamula; srioptom@lvpei.org

Received 7 April 2013; Revised 4 June 2013; Accepted 10 June 2013

Academic Editor: Alberto Raggi

Copyright (C) 2013 Srinivas Marmamula et al. This is an open access article distributed under the Creative Commons Attribution License, which permits unrestricted use, distribution, and reproduction in any medium, provided the original work is properly cited.

Background. There is limited research conducted on uncorrected refractive errors, presbyopia, and spectacles use among the elderly population in residential care in developing countries such as India. We conducted a cross-sectional study among elderly in residential care to assess the spectacle coverage and spectacles usage in the south Indian state of Andhra Pradesh. Methods. All 524 residents in the 26 "homes for aged" institutions in the district were enumerated. Eye examination was performed that included visual acuity (VA) assessment for distant and near vision. A questionnaire was used to collect information on spectacles use. Results. 494/524 individuals were examined, $78 \%$ were women, and $72 \%$ had no education. The mean age of participants was 70 years. The spectacle coverage for refractive errors was $35.1 \%$ and $23.9 \%$ for presbyopia. The prevalence of current use and past use of spectacles was $38.5 \%$ (95\% CI: $34.2-42.8 ; n=190)$ and $17.2 \%$ (95\% CI: 13.9-42.8), respectively. Conclusions. There is low spectacle coverage for both refractive errors and presbyopia among elderly individuals in residential care in the south Indian state of Andhra Pradesh. Appropriate service delivery systems should be developed to reach out this vulnerable group of seniors on a priority basis.

\section{Introduction}

Uncorrected refractive errors remain the leading cause of visual impairment worldwide [1]. It is one of the priorities of VISION 2020, The Right to Sight initiative. Uncorrected refractive errors that result in visual impairment are termed as correctable visual impairment by few authors [2]. Presbyopia is now recognized as a major problem affecting over a billion people globally out of which 517 million are in need of correction for near vision [3]. By far, spectacles remain the most common and cost-effective intervention for refraction errors and presbyopia worldwide. Despite this, the data on spectacle usage patterns is limited.
There is limited research conducted on uncorrected refractive errors and spectacles use among the elderly population in residential care in developing countries such as India. Elderly people living in residential care are a vulnerable group and tend to have a higher prevalence of visual impairment compared to the general population as evidenced in studies from developed countries [4-9]. Higher prevalences were also found in the studies conducted in developing countries [10-12]. In both developed and developing countries, uncorrected refractive errors were major causes of visual impairment.

In a recent study among the elderly in residential care in the state of Andhra Pradesh, we discovered that uncorrected 
refractive errors were the second leading cause of visual impairment after cataract [13]. This follow-up paper from the same study extends beyond prevalence and causes of visual impairment and reports on uncorrected refractive errors, spectacles use and coverage. We also report on uncorrected presbyopia among this elderly population. As both refractive errors and presbyopia can be easily addressed through primary eye care approach of eye screening by paramedical personnel and dispensing of spectacles, our results have implications for planning such services for elderly population in residential care in India. The data from both papers together provide a comprehensive overview of the eye care needed among elderly population in residential care in the south Indian state of Andhra Pradesh.

\section{Methods}

The study was approved by the institutional review board of L V Prasad Eye Institute, Hyderabad, Indian and followed the tenets of declaration of Helsinki. Written informed consent was obtained from all the study participants before commencing with the study procedures.

The details of the eye examination protocol are described elsewhere [13]. In brief, a team consisting of an ophthalmic officer (paramedical ophthalmic personnel) and a field assistant visited the "home for the aged" institutions and conducted eye examinations. Distant and near visual acuity (VA) were assessed. A questionnaire was used to collect information on present and past spectacles use, the spectacles provider, and the purpose of using the spectacles. The spectacles providers were classified as private eye clinics (small clinics usually staffed by paramedical ophthalmic personnel who are available and eye examination is performed; few clinics also have a visiting ophthalmologist at a regular frequency), nongovernment eye hospitals, optical shops (shops where there are no formally trained eye care personnel available and spectacles are prescribed based on subjective correction or based autorefraction), and eye camps (make-shift eye clinics where refraction is performed and spectacles are provided free of cost).

To calculate the spectacle coverage, "met need" was defined as the number of subjects who were using their spectacles to correct refractive error and/or presbyopia. For refractive errors, all subjects who had unaided VA $<6 / 18$ in either eye, which improved to $6 / 18$ or better with spectacles, were considered to have had their need met; that is, their refractive error was corrected. "Unmet need" was defined as the number of subjects who had unaided VA $<6 / 18$ in either eye but improved to $6 / 18$ or better with pinhole and had no spectacles. Total need, which is the sum of met and unmet needs, gives the prevalence of refractive error in the population. The concept of spectacle coverage is similar to that used in previous studies $[14,15]$. The spectacle coverage (\%) for refractive errors was calculated as follows: spectacle coverage $(\%)=($ met need $/$ met need + unmet need $) \times 100$.

For presbyopia, "met need" was defined as unaided near vision $<\mathrm{N} 8$, but improved to N8 or better with the spectacles they were using. "Unmet need" was defined as unaided near vision $<\mathrm{N} 8$ and had no spectacles for near vision but improved to N8 or better with a near addition, that is, uncorrected presbyopia. Total need, which is the total of unmet and met needs, gives the prevalence of presbyopia in the population. The same formula described earlier was used to calculate the spectacle coverage for presbyopia. The N8 criterion was used as a conservative estimate of corrected presbyopia. It also corresponds to newsprint in India, and this criterion was also used in previous studies $[14,16]$.

Data management and analysis were done using SPSS 16.0 (SPSS Inc., Chicago, IL, USA). Point prevalence estimates and 95\% CI (confidence intervals) were calculated. Multiple logistic regression was used to assess the association between current use of spectacles and demographic variables. Adjusted odds ratio (OR) with 95\% CI is presented.

\section{Results}

3.1. Characteristics of the Study Sample. A total of 524 subjects were enumerated from 26 institutions for the elderly, and 494 (94.3\%) were examined. Data was not available on 15 participants who had systemic conditions and hence eye examination was not possible. Another 15 subjects were not available during the visit. Among those who were examined, $78.1 \%$ of the subjects were female, and $72.1 \%$ had no education. Nearly $57 \%$ of those examined were aged 70 years or older. The mean age of the participants was 70 years (standard deviation $=8.6$ years).

3.2. Refractive Errors, Presbyopia, and Spectacle Coverage. Refractive errors were present in 114/494 (23.1\%; 95\% CI: 19.4-26.8) individuals. These were uncorrected (unmet need) in 74 individuals (7.8\%; 95\% CI: 5.4-10.2) and corrected (met need) in 40 individuals. Based on these, the spectacle coverage for refractive errors was $35.1 \%$. The spectacle coverage for refractive errors was higher among older individuals, men, and those with any education. The unmet need for refractive errors was associated significantly with the level of education $(P<0.01)$; no significant association was found with age and gender (Table 1).

Presbyopia was present in 271 individuals (55.1\%; 95\% CI: 50.7-59.4). It was uncorrected (unmet need) in 207 individuals (41.9\%; 95\% CI: 73.5-46.3) and corrected (met need) in 65 individuals. Based on this the spectacle coverage for presbyopia was $23.9 \%$. The spectacle coverage for presbyopia was higher among men and those with any education. The unmet need for presbyopia was significantly associated with age $(P<$ 0.01 ) and levels of education but not with gender (Table 1 ).

3.3. Spectacles Use. The prevalence of current spectacles use was $38.5 \%$ (95\% CI: $34.2-42.8 ; n=190)$. It was significantly higher in older individuals $(P<0.01)$ and those with education $(P<0.01)$. Though spectacle use was higher among men than women, it was not statistically significant $(P=0.15)$. A total of 85/494 (17.2\%; 95\% CI: 13.9-42.8) individuals reported the use of spectacles in the past. The common reasons quoted for discontinuation of spectacles were "lost spectacles and no money to buy a new pair" ( $n=40 / 85 ; 44.7 \%)$, "no benefit 
TABLE 1: Spectacle coverage for refractive errors and presbyopia.

\begin{tabular}{lccccccc}
\hline & Total in the group & \multicolumn{3}{c}{ Refractive errors } & \multicolumn{3}{c}{ Presbyopia } \\
& $n$ & $\begin{array}{c}\text { Met need } \\
n(\%)\end{array}$ & $\begin{array}{c}\text { Unmet need } \\
n(\%)^{\dagger}\end{array}$ & $\begin{array}{c}\text { Spectacle coverage } \\
(\%)\end{array}$ & $\begin{array}{c}\text { Met need } \\
n(\%)\end{array}$ & $\begin{array}{c}\text { Unmet need } \\
n(\%)^{\ddagger}\end{array}$ & $\begin{array}{c}\text { Spectacle coverage } \\
(\%)\end{array}$ \\
\hline $\begin{array}{l}\text { Age group (years) } \\
\text { 50-69 }\end{array}$ & 214 & $11(5.1)$ & $35(16.4)$ & 23.9 & $26(12.1)$ & $77(36.0)$ & 25.2 \\
$\quad 70$ and above & 280 & $29(10.4)$ & $39(13.9)$ & 42.6 & $39(13.9)$ & $130(46.4)$ & 23.1 \\
$\quad \begin{array}{l}\text { Gender } \\
\text { Male }\end{array}$ & & & & & & & \\
$\quad$ Female & 108 & $9(8.3)$ & $12(11.1)$ & 42.9 & $26(24.1)$ & $43(39.8)$ & 37.7 \\
$\quad \begin{array}{l}\text { Education level } \\
\text { No education }\end{array}$ & 386 & $31(8.0)$ & $62(16.1)$ & 33.3 & $39(10.1)$ & $164(42.5)$ & 19.2 \\
$\quad$ Any education & 356 & $17(4.8)$ & $65(18.3)$ & 5.3 & $19(5.3)$ & $168(47.2)$ & 10.2 \\
Total & 138 & $23(16.7)$ & $9(6.5)$ & 33.3 & $46(33.3)$ & $39(28.3)$ & 54.1 \\
\hline
\end{tabular}

${ }^{\dagger}$ Not statistically significant for age group and gender; $P<0.01$ for education.

${ }^{\ddagger} P<0.01$ for age and gender; not statistically significant for gender.

Met need (refractive errors): defined as unaided visual acuity $<6 / 18$ in either eye, which improved to $6 / 18$ or better with spectacles.

Unmet need (refractive errors): defined as the number of subjects who had unaided visual acuity $<6 / 18$ in either eye but improved to $6 / 18$ or better with pinhole and had no spectacles.

Met need (presbyopia): defined as unaided near vision $<$ N8, but improved to N8 or better with the spectacles they were using.

Unmet need (presbyopia): defined as unaided near vision $<$ N8 and had no spectacles, but improved to N8 or better with a near addition.

Spectacle coverage (refractive errors and presbyopia) $(\%)=$ met need $/($ met need + unmet need $) \times 100$.

from use of spectacles" ( $n=23 / 85 ; 27.1 \%)$, "broken or scratches on the lenses" ( $n=19 / 85 ; 24.8 \%)$, and "discomfort with spectacles" ( $n=3 / 85 ; 3.5 \%$ ). The past use of spectacles was not associated with age, gender, or education (Table 2).

On applying multiple logistic regression, the current use of spectacles was associated with older age, any level of education and history of surgery in either eye. Though the odds of spectacles use were higher among women than men, it was not statistically significant (Table 3).

Among the current users of spectacles, the single vision for distance was the most commonly used type of spectacles $(n=97 ; 51.1 \%)$ followed by bifocals $(n=86 ; 45.3 \%)$. Single vision spectacles for near vision only were being used by seven individuals (3.7\%). Private eye clinics ( $n=138 ; 72.6 \%$ ) were the leading service providers for spectacles followed by local nongovernment organizations $(n=25 ; 13.2)$. Fourteen individuals $(7.4 \%)$ procured their spectacles directly from an optical shop, and the remaining 13 (6.8\%) individuals got their spectacles at no cost from a government screening camp.

\section{Discussion}

We found a high prevalence of uncorrected refractive errors, presbyopia, and low spectacle coverage in elderly population in residential care in the south Indian state of Andhra Pradesh. Previously, we had reported a high prevalence of visual impairment in this population out of which over $26 \%$ was due to uncorrected refractive errors [13]. Several papers have reported the prevalence of uncorrected refractive errors in the elderly in general population [2,11, 17-19], 10\% in Taiwan [11], 3.0\% and 3.2\% in the United Kingdom [8, 17, 20], $13.4 \%$ in Hong Kong [12] compared to $7.8 \%$ in the present study. The cross-comparisons of the results across the studies are of limited value owing to differences in the definition of uncorrected refractive errors, study settings, and population. The data from population-based cross-sectional studies cannot be used to compare our findings from residential care as both populations are very different. The residential care institutions tend to have more elderly people who are predominantly women.

Uncorrected refractive errors are the easiest of the public eye heath challenges that can be addressed, especially in elderly people in residential care. It is cost effective and the benefit is immediate which in turn can vastly improve the quality of life of these people [21].

We found a prevalence of presbyopia that was similar to a previous study from the state of Andhra Pradesh [16]. However our reported prevalence was higher than that reported from a previous study that had a younger age group [14], which was expected. Both of these studies were populationbased compared to a specific group of elderly population in the present study.

Spectacles use was not frequently reported in studies on the elderly. The study from Andhra Pradesh reported $17.4 \%$ prevalence of current spectacles use [22, 23], and the Chennai study revealed a prevalence of $17.6 \%$ and $52.6 \%$ in the rural and urban samples, respectively [23]. While the study from Andhra Pradesh included participants of all ages, the Chennai study was limited to those aged $\geq 40$ years $[22,23]$. Our finding of prevalence of $38.5 \%$ was higher than that reported from Andhra Pradesh and rural segment of Chennai study. However, it is less than that found in urban area in the Chennai study. The spectacle coverage for refractive errors was previously reported as $28.4 \%$ and $29 \%$ compared to $35 \%$ in the present study $[14,15]$. Similarly the spectacle coverage 
TABle 2: Present and past spectacles uses.

\begin{tabular}{|c|c|c|c|c|c|}
\hline & \multirow{2}{*}{$\begin{array}{c}\text { Total sample } \\
n\end{array}$} & \multicolumn{2}{|c|}{ Spectacles use-present ${ }^{\dagger}$} & \multicolumn{2}{|c|}{ Spectacles use-past ${ }^{\ddagger}$} \\
\hline & & $n$ & $\%$ & $n$ & $\%$ \\
\hline \multicolumn{6}{|l|}{ Age group (years) } \\
\hline $50-69$ & 214 & 66 & 30.8 & 44 & 20.6 \\
\hline 70 and above & 280 & 124 & 44.3 & 41 & 14.6 \\
\hline \multicolumn{6}{|l|}{ Gender } \\
\hline Male & 108 & 48 & 44.4 & 17 & 15.7 \\
\hline Female & 386 & 142 & 36.8 & 68 & 17.6 \\
\hline \multicolumn{6}{|l|}{ Education level } \\
\hline No education & 356 & 109 & 30.6 & 63 & 17.7 \\
\hline Any education & 138 & 81 & 58.7 & 22 & 15.9 \\
\hline Total & 494 & 190 & 38.5 & 85 & 17.2 \\
\hline
\end{tabular}

TABLE 3: Multivariate analysis showing associations with spectacles use.

\begin{tabular}{lccc}
\hline & $\begin{array}{c}\text { Adjusted } \\
\text { odds ratio }\end{array}$ & $\begin{array}{c}95 \% \text { confidence } \\
\text { interval }\end{array}$ & $P$ value \\
\hline $\begin{array}{l}\text { Age group (years) } \\
50-69\end{array}$ & 1.0 & & \\
$\quad 70$ and above & 1.7 & $1.1-2.6$ & 0.00 \\
Gender & 1.0 & & \\
$\quad$ Male & 1.3 & $0.8-2.2$ & 0.28 \\
$\quad$ Female & & & \\
Education level & 1.0 & & 0.00 \\
$\quad$ No education & 5.4 & $3.2-8.6$ & \\
$\quad$ Any education & & & \\
Surgery status & 1.0 & & 0.02 \\
$\quad$ Never operated & 3.7 & $2.4-5.6$ & \\
$\quad$ Operated in either eye & & & \\
\end{tabular}

for presbyopia was reported as $11.1 \%$ and $19 \%$ compared to $24 \%$ in the present study $[14,15]$. The higher coverage can be attributed to the older population in the present study compared to the other two studies.

The use of pinhole based definition for refractive errors as a surrogate measure of refractive errors, though helpful for rapid evaluation of the individuals who could benefit from spectacle correction, is not free from limitations. The results may vary if refraction was conducted on all the individuals. The inclusion of data regarding quality of life and visual function of participants could have provided more insights; however, these were not assessed due to time constraints. The visual needs of older people in residential care may differ from those in the general population and other populations, so this may be an important area for future research.

In summary, we found a high prevalence of uncorrected refractive errors, uncorrected presbyopia, and low spectacle coverage. Appropriate service delivery systems including eye screening and spectacles dispensing programmes should be developed to reach out this vulnerable group of seniors on a priority basis. The correction of refractive errors and presbyopia may indirectly impact their general well-being, quality of life and contribute to a more independent living.

\section{Authors' Contribution}

Srinivas Marmamula and L. V. Chandra Sekhar Ravuri contributed to the design and conduct of the study, data collection, and management; Srinivas Marmamula, L. V. Chandra Sekhar Ravuri and Mei Ying Boon were involved in analyses and interpretation of data; Srinivas Marmamula, Mei Ying Boon, and Rohit C. Khanna were involved in preparation of paper; and Srinivas Marmamula, Mei Ying Boon, L. V. Chandra Sekhar Ravuri, and Rohit C. Khanna reviewed and approved the paper.

\section{Conflict of Interests}

The authors declare that they have no conflict of interests.

\section{Acknowledgments}

The financial support for this study was provided in part by the Andhra Pradesh Right to Sight Society, India and by Hyderabad Eye Research Foundation, India. The authors thank the volunteers for their participation in the study. The authors acknowledge Dr. Sreedevi Yadavalli for her assistance with language editing of the paper.

\section{References}

[1] D. Pascolini and S. P. Mariotti, "Global estimates of visual impairment: 2010," British Journal of Ophthalmology, vol. 96, no. 5, pp. 614-618, 2012.

[2] J. Schneider, S. R. Leeder, B. Gopinath, J. J. Wang, and P. Mitchell, "Frequency, course, and impact of correctable visual 
impairment (uncorrected refractive error)," Survey of Ophthalmology, vol. 55, no. 6, pp. 539-560, 2010.

[3] B. A. Holden, T. R. Fricke, S. M. Ho et al., "Global vision impairment due to uncorrected presbyopia," Archives of Ophthalmology, vol. 126, no. 12, pp. 1731-1739, 2008.

[4] P. Mitchell, P. Hayes, and J. J. Wang, "Visual impairment in nursing home residents: the Blue Mountains Eye study," Medical Journal of Australia, vol. 166, no. 2, pp. 73-76, 1997.

[5] H. R. Nottle, C. A. McCarty, J. B. Hassell, and J. E. Keeffe, "Detection of vision impairment in people admitted to aged care assessment centres," Clinical and Experimental Ophthalmology, vol. 28, no. 3, pp. 162-164, 2000.

[6] C. Owsley, G. McGwin, K. Scilley, G. C. Meek, A. Dyer, and D. Seker, "The visual status of older persons residing in nursing homes," Archives of Ophthalmology, vol. 125, no. 7, pp. 925-930, 2007.

[7] J. M. Tielsch, J. C. Javitt, A. Coleman, J. Katz, and A. Sommer, "The prevalence of blindness and visual impairment among nursing home residents in baltimore," The New England Journal of Medicine, vol. 332, no. 18, pp. 1205-1209, 1995.

[8] J. C. van der Pols, C. J. Bates, P. V. McGraw et al., "Visual acuity measurements in a national sample of British elderly people," British Journal of Ophthalmology, vol. 84, no. 2, pp. 165-170, 2000.

[9] M. R. VanNewkirk, L. Weih, C. A. McCarty, Y. L. Stanislavsky, J. E. Keeffe, and H. R. Taylor, "Visual impairment and eye diseases in elderly institutionalized Australians," Ophthalmology, vol. 107, no. 12, pp. 2203-2208, 2000.

[10] M. K. Dev, G. S. Shrestha, N. Paudel, N. D. Joshi, M. Thapa, and D. N. Shah, "Visual status and ocular morbidity in older adults living in residential care," Graefe's Archive for Clinical and Experimental Ophthalmology, vol. 250, no. 9, pp. 1387-1393, 2012.

[11] T. Kuang, S. Tsai, W. Hsu, C. Cheng, J. Liu, and P. Chou, "Correctable visual impairment in an elderly Chinese population in Taiwan: the Shihpai eye study," Investigative Ophthalmology and Visual Science, vol. 48, no. 3, pp. 1032-1037, 2007.

[12] J. J. Michon, J. Lau, S. C. Wing, and L. B. Ellwein, "Prevalence of visual impairment, blindness, and cataract surgery in the Hong Kong elderly," British Journal of Ophthalmology, vol. 86, no. 2, pp. 133-139, 2002.

[13] S. Marmamula, C. S. Ravuri, M. Y. Boon, and R. C. Khanna, "A cross-sectional study of visual impairment in elderly population in residential care in the South Indian state of Andhra Pradesh: a cross-sectional study," BMJ Open, vol. 3, no. 3, 2013.

[14] S. Marmamula, J. E. Keeffe, and G. N. Rao, "Uncorrected refractive errors, presbyopia and spectacle coverage: results from a rapid assessment of refractive error survey," Ophthalmic Epidemiology, vol. 16, no. 5, pp. 269-274, 2009.

[15] S. Marmamula, S. R. Madala, and G. N. Rao, "Prevalence of uncorrected refractive errors, presbyopia and spectacle coverage in marine fishing communities in South India: rapid assessment of visual impairment (RAVI) project," Ophthalmic and Physiological Optics, vol. 32, no. 2, pp. 149-155, 2012.

[16] P. K. Nirmalan, S. Krishnaiah, B. R. Shamanna, G. N. Rao, and R. Thomas, "A population-based assessment of presbyopia in the state of Andhra Pradesh, south India: the Andhra Pradesh eye disease study," Investigative Ophthalmology and Visual Science, vol. 47, no. 6, pp. 2324-2328, 2006.

[17] B. J. W. Evans and G. Rowlands, "Correctable visual impairment in older people: a major unmet need," Ophthalmic and Physiological Optics, vol. 24, no. 3, pp. 161-180, 2004.
[18] S. Foran, K. Rose, J. J. Wang, and P. Mitchell, “Correctable visual impairment in an older population: the Blue Mountains Eye study," American Journal of Ophthalmology, vol. 134, no. 5, pp. 712-719, 2002.

[19] D. Z. Reinstein, N. L. Dorward, R. P. L. Wormald et al., "“Correctable undetected visual acuity deficit' in patients aged 65 and over attending an accident and emergency department," British Journal of Ophthalmology, vol. 77, no. 5, pp. 293-296, 1993.

[20] J. R. Evans, A. E. Fletcher, and R. P. L. Wormald, "Causes of visual impairment in people aged 75 years and older in Britain: an add-on study to the MRC trial of assessment and management of older people in the community," British Journal of Ophthalmology, vol. 88, no. 3, pp. 365-370, 2004.

[21] C. Owsley, G. McGwin Jr., K. Scilley, G. C. Meek, D. Seker, and A. Dyer, "Effect of refractive error correction on health-related quality of life and depression in older nursing home residents," Archives of Ophthalmology, vol. 125, no. 11, pp. 1471-1477, 2007.

[22] R. Dandona, L. Dandona, V. Kovai, P. Giridhar, M. N. Prasad, and M. Srinivas, "Population-based study of spectacles use in southern India," Indian Journal of Ophthalmology, vol. 50, no. 2, pp. 145-155, 2002.

[23] R. Prema, G. Ronnie, R. S. Ve et al., "Comparison of refractive errors and factors associated with spectacle use in a rural and urban South Indian population," Indian Journal of Ophthalmology, vol. 56, no. 2, pp. 139-144, 2008. 


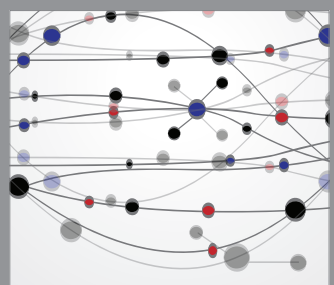

The Scientific World Journal
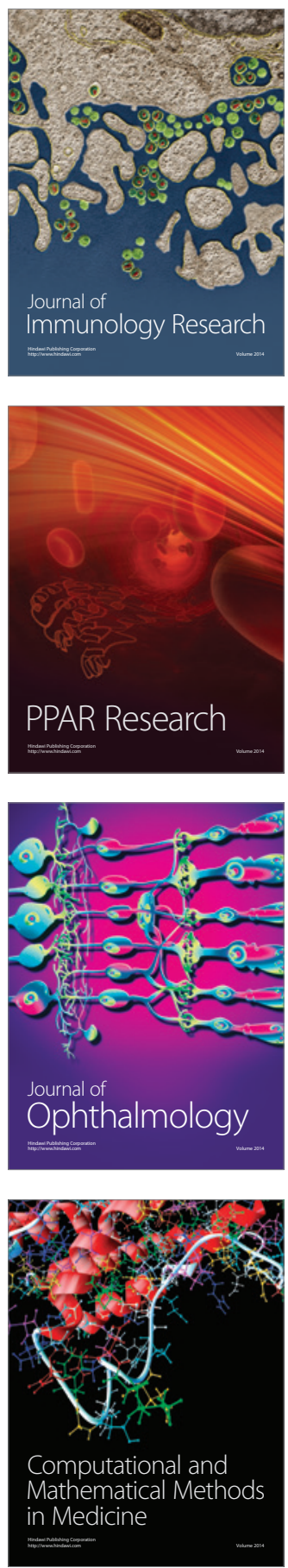

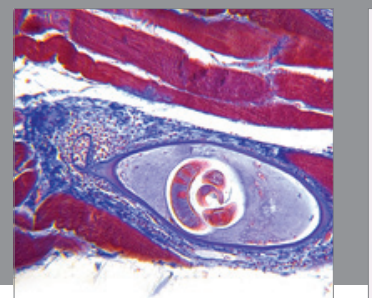

Gastroenterology

Research and Practice
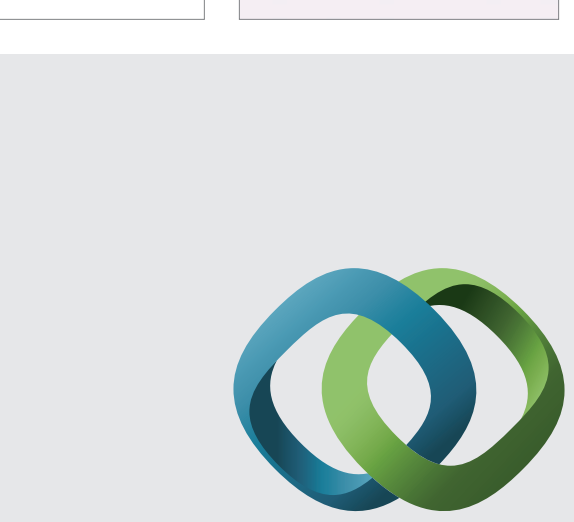

\section{Hindawi}

Submit your manuscripts at

http://www.hindawi.com
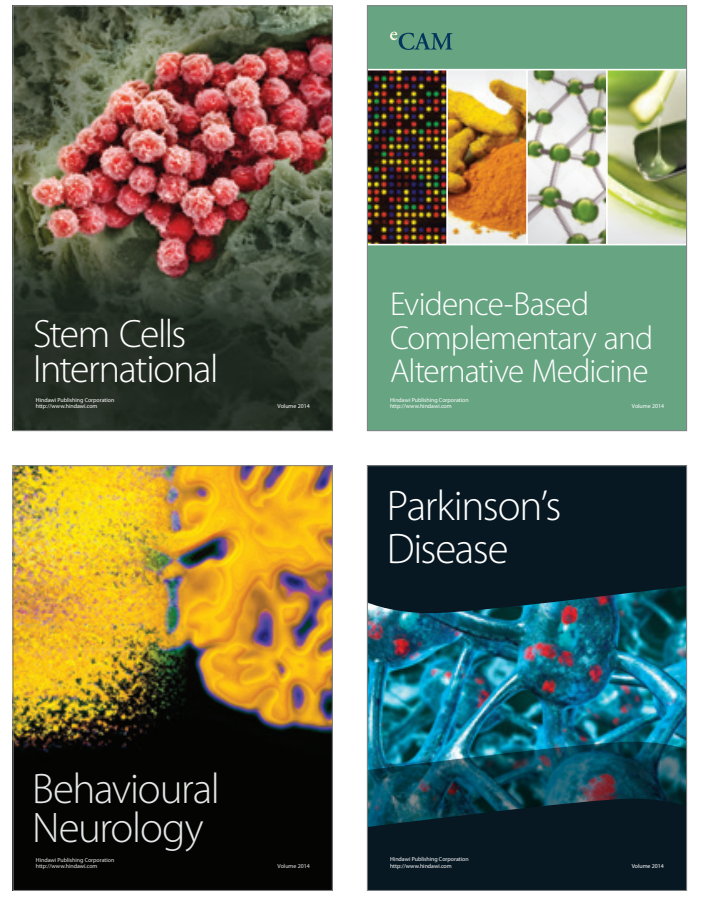
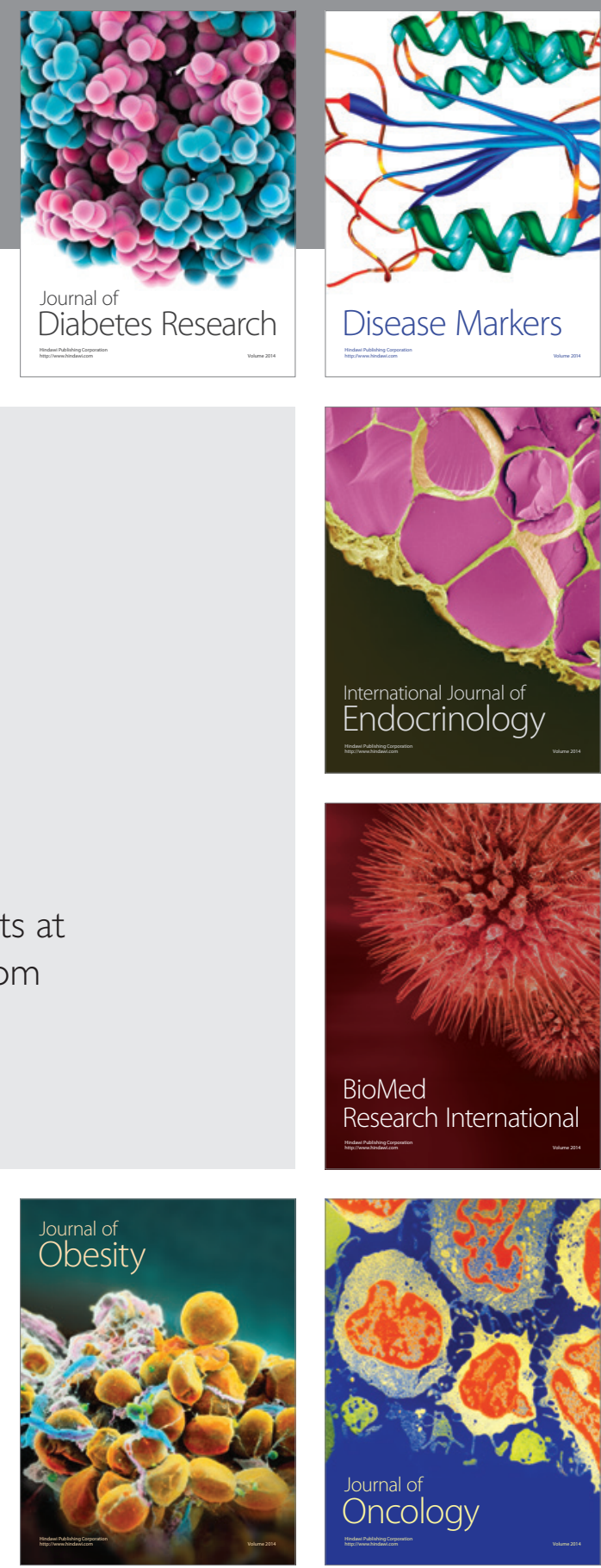

Disease Markers
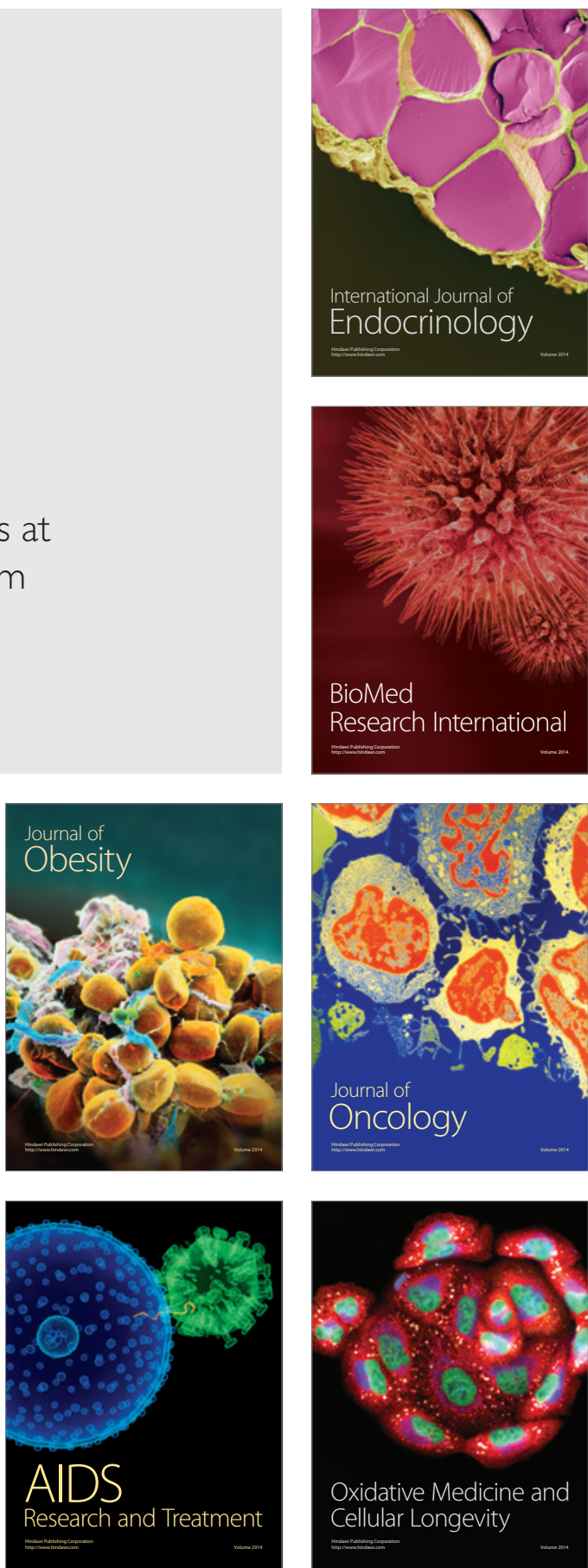